\title{
A temperature-limited assessment of the risk of Rift Valley fever transmission and establishment in the continental United States of America
}

\author{
Sarah K. Konrad, Scott N. Miller \\ Department of Ecosystem Science and Management, University of Wyoming, Laramie, Wyoming, USA
}

\begin{abstract}
The rapid spread of West Nile virus across North America after its introduction in 1999 highlights the potential for foreign arboviruses to become established in the United States of America. Of particular concern is Rift Valley fever virus (RVFV), which has been responsible for multiple African epidemics resulting in death of both humans and livestock, as well as major economic disruption due to livestock loss and trade restrictions. Modern globalization, travel, and commerce allow viruses to easily jump from one continent to another; and it is likely only a matter of time before RVFV reaches North American shores. We used a degree-day model in combination with livestock population data and a pathways analysis to identify regions and times where RVFV is most likely to enter and become established in the United States of America. Transmission risk of the disease varies across the country from 325 annual risk days in parts of Florida to zero risk days in the far North and in high mountain regions. Areas of particular concern are where there are a high number of possible transmission days, a large livestock population, and proximity to likely locations for the disease to enter the country via mosquito vector or human host. These areas should be monitored closely during transmission "risk seasons" so that if the virus does enter the country and begins to become established, it can be quickly controlled and eliminated before spreading further. Areas most at risk include the Baltimore and New York City metro areas as well as much of the region between these urban centers; most of Texas, especially around Houston; Florida; Atlanta; southwest Nebraska; southern California and Arizona; and the central valley of California.
\end{abstract}

Keywords: Rift Valley fever, virus transmission, Culex tarsalis, United States of America, geographical information systems, West Nile virus.

\section{Introduction}

Rift Valley fever virus (RVFV) (Bunyaviridae: Phlebovirus) was first characterized by Daubney et al. (1931) in what is now the Republic of Kenya. RVFV is an insect-borne virus endemic to sub-Saharan Africa, whose vectors include multiple mosquito species as well as some species of biting flies (Meegan and Bailey, 1988; Turell et al., 1996, 2008). Laboratory tests show at least one North American mosquito species, Culex tarsalis, to be a competent vector for RVFV (Turell et al., 2010). Domestic animals are the primary reservoir host for this zoonotic disease, which causes high mortality and abortion in cattle, sheep, and goats, and also affects humans, sometimes fatally (Geisbert and Jahrling, 2004).

\footnotetext{
Corresponding author:

Sarah Konrad

Department of Ecosystem Science and Management

University of Wyoming

Box 335, 1000 E. University Drive

Laramie, WY 82071, USA

Tel. +1 307 766-2295; Fax + 1307 766-6403

E-mail:skonrad@uwyo.edu
}

The objective of this study is to spatially and temporally identify the regions in the continental United States of America (USA) where RVFV is most likely to gain entry and become established, so that surveillance and control tools can be targeted to greatest effect. Given the highly globalized nature of business commerce and travel, it is probable that RVFV will reach the USA in much the same manner as the West Nile virus (WNV), which arrived in New York in 1999 and spread across North America within just a few years (Enserink, 2002). Should RVFV become established in the USA, it would pose a serious health threat to both humans and livestock with financial ramifications estimated at billions of dollars to the livestock industry (Pearson, 2000).

RVFV epizootics in Africa are associated with periods of heavy rainfall which lead to the hatching of large populations of vector mosquitoes (Davies et al., 1985). However, periods of extreme rainfall and flooding are not generally associated with outbreaks of arboviruses in temperate climates such as the continental USA (Nasci and Moore, 1998). Rather, previous research has shown temperature to be a limiting factor of arbovirus transmission (e.g. Hurlbut, 1973; 
Reisen et al., 2006; Konrad et al., 2009). In order for a mosquito to transmit an arbovirus, it must have completed the extrinsic incubation period (EIP), during which time the arthropod becomes infectious. The length of the EIP depends on three factors: (i) the virus type (e.g. Moudy et al., 2007); (ii) the mosquito species (e.g. Turell et al., 1985); and (iii) the temperature to which the mosquito is exposed after introduction to the virus (e.g. Reisen et al., 2006). When a mosquito takes a blood meal from an infected host it ingests infected blood but is not capable of infecting other animals until the virus is disseminated through the mosquito's body, specifically entering into its salivary glands. This dissemination requires thermal energy, and since mosquitoes are cold-blooded animals, energy must be externally applied. If the EIP is completed during the time period when the mosquito continues to feed, then the mosquito may infect other animals. Thus, the temperature to which the mosquito is exposed during its feeding cycle is critical to determining whether a virus will become established in a new territory.

A pathways analysis of the potential for release of RVFV into the USA found that the most likely means of entry are via infected persons or mosquitoes arriving by an airplane and by infected mosquitoes arriving with a container ship (Kasari et al., 2008). Between 2001 and 2004 , over $97 \%$ of all incoming passengers from RVFVendemic countries landed at one of six international airports (New York City, Washington DC, Atlanta, Baltimore, Newark and Houston) and the most frequented seaports for African traffic were Charleston, Philadelphia and New York. As over half of the visitors to the USA from RVFV-endemic countries stated that the purpose of their travel was to visit family, Kasari et al. (2008) concluded that the 10 states with the highest populations of African immigrants were likely final destinations for many of these travelers, i.e. California, Florida, Georgia, Maryland, Massachusetts, Minnesota, New Jersey, New York, Texas, and Virginia. In addition, Alabama and Maine were the final destination for more than $10 \%$ of commodities coming from countries endemic for RVFV. Taking all of the above into account, Kasari et al. (2008) concluded that people and domestic livestock in 14 states are particularly vulnerable to RVFV exposure: Alabama, California, Florida, Georgia, Maine, Maryland, Massachusetts, Minnesota, New Jersey, New York, Pennsylvania, South Carolina, Texas, and Virginia.

RVFV entry points that have warm temperatures, high livestock density, and an abundance of an appropriate mosquito species are the most likely regions for
RVFV to become established in the USA. In this paper, we evaluate the risk of RVFV transmission based on likely entry points, livestock abundance and analysis of historical degree-day temperatures. Not every potential risk factor is examined; notably lacking is vector abundance, which was difficult to adequately characterize over the spatial and temporal scale of this study. Abundance is often believed to depend on the availability of water, but studies of North American mosquitoes have shown that this is not a simplistic relationship. For example, in Colorado, wet spring conditions increase the abundance of $C x$. tarsalis in the plains, but dry summer conditions increase the abundance of both $C x$. tarsalis and $C x$. pipiens throughout the entire state (Shaman et al., 2010). The populations of floodwater species such as Aedes vexans increase with precipitation, but species which breed in eutrophic waters, such as $C x$. pipiens, are negatively correlated with surface wetness (Shaman et al., 2002). Logistic regression studies have shown that the abundance of several common North American mosquito species, including Cx. tarsalis, is primarily influenced by degree-day temperatures rather than precipitation (Lysyk, 2010). Because of this, we relied upon the critical and limiting factor of temperature to identify regions and dates when virus transmission risk is theoretically possible, and upon livestock density to identify areas of likely establishment and impact.

\section{Materials and methods}

In this study, we built upon the foundation of previous work (Konrad et al., 2011) significantly expanding the study area from five states to the entire contiguous USA. However, the methods remain mostly unchanged from Konrad et al. (2011). We used a degree-day model (Zou et al., 2007; Konrad et al., $2009,2011)$ to assess historical temperature data and determine when and where local temperatures permit virus transmission. Daily maximum and minimum temperatures were downloaded from DAYMET (http://www.daymet.org, Thornton et al. 1997) on a $10-\mathrm{km}$ grid for the contiguous USA for the most recent 10-year time period available (January 1, 1994 to December 31, 2003). These data were compiled to produce an average temperature maximum and minimum for each day of the year at every grid point. Other inputs to the degree-day model included the length of the vector feeding period (the time between the mosquito's first and last blood meal), the degreedays to EIP for the virus and vector in question, and the minimum transmission threshold temperature. 
Model output consisted of spatial and temporal transmission risk maps that can be created on a yearly basis (number of annual risk days) or a daily basis (areas either at risk or not at risk on a given day).

The degree-days necessary to reach EIP are strongly dependent on both the virus type and the species of mosquito. Since RVFV has yet to become established in the USA, this parameter cannot be directly measured nor calibrated with field data (e.g. Konrad et al., 2011). Turell et al. (2011) evaluated the potential for North American arthropods (including Cx. erraticus, Cx. erythrothorax, Cx. nigripalpus, Cx. pipiens, Cx. quinquefasciatus, Cx. tarsalis, Ae. dorsalis, Ae. vexans, Anopheles quadrimaculatus and Culicoides sonorensis) to transmit RVF, and found that only $C x$. tarsalis transmitted the disease efficiently. The relationship between temperature and transmission rates of RVFV in Cx. tarsalis has yet to be quantified in the field but, similar to $\mathrm{WNV}$, the virus is not temperaturelimited in the warm, African continent where it is endemic. Other researchers are attempting to establish a temperature/transmission relationship in the laboratory but in the current absence of reliable data we used previously identified parameters for WNV transmission in Cx. tarsalis as a "best guess" proxy for RVFV (Turell MJ, personal communication). The critical parameters for WNV transmission were successfully calibrated and tested with field data from California by Konrad et al. (2009), in which the number of degree-days to reach EIP was determined to be 76 , with a minimum temperature for the calculation of degree-days of $14.3^{\circ} \mathrm{C}$, and a maximum of 12 days between the first and last blood meal, which is the sum of three four-day gonotrophic cycles (Reisen et al., 1993). If new parameters specific to RVFV become available, they can be easily substituted into the model to produce updated results. The degree-day calculations used in this study follow Allen (1976) and depend on the minimum and maximum temperatures observed during a 24-hour period. Equation 1 was used to calculate degree-days to EIP $\left({ }^{\circ} D\right)$ when the minimum observed temperature is above the minimum threshold for the calculation of degree-days $\left(T_{l}\right)$

$$
{ }^{\circ} \mathrm{D}=\frac{T_{\max }+T_{\min }}{2}-T_{l} .
$$

When the minimum temperature $\left(T_{\min }\right)$ is less than $T_{l}$, but the maximum observed temperature $\left(T_{\max }\right)$ is greater than $T_{l}$, equation 2 is used:

$$
{ }^{\circ} \mathrm{D}=\frac{1}{\pi}\left[\left(\frac{\left(T_{\max }+T_{\min }\right)}{2}-T_{l}\right) *\left(\frac{\pi}{2}-\theta_{i}\right)+a * \cos \theta_{i}\right],
$$

where

$$
\theta_{i}=\sin ^{-1}\left[\frac{\left(T_{l}-\frac{\left(T_{\max }+T_{\min }\right)}{2}\right)}{\alpha}\right] \text {, }
$$

and

$$
\propto=\frac{T_{\max }-T_{\min }}{2} .
$$

When $T_{\max }$ is less than $T_{l}$, no calculation is performed and the day is assigned zero degree-days.

Our approach was to calculate the degree-day value for each cell in the contiguous USA for each calendar day using the 10-year averages for maximum and minimum temperature for each day. We calculated the cumulative 12-day degree-day total (corresponding to the feeding period window) for each day by adding the degree-days from each of the previous 11 days to the day in question. In this way we could identify the spatial and temporal locations of areas at risk for virus transmission.

The regions most at risk for the establishment and subsequent economic impact of RVFV are those where the mosquito vectors are present, degree-day temperatures are high enough for the virus to reach EIP in the host mosquitoes for a high proportion of the year, and there is a large concentration of livestock hosts. Although mosquito vectors are able to transmit RVFV when the temperatures are sufficiently high, RVFV is unlikely to gain a foothold without the presence of a suitable reservoir for the virus. As domestic livestock have proved to be the primary reservoir in African countries (Geisbert and Jahrling, 2004), we assumed that the same will be true in the USA. The degree-day temperature assessment reflects the risk of RVFV transmission; greater livestock density in RVFV risk areas implies an increased chance of RVFV establishment in a domestic animal reservoir and a greater potential economic impact to the livestock industry. Therefore, we evaluated both transmission risk and compound risk (temperature and livestock based). Compound risk was assessed by normalizing the number of transmission risk days per year and the livestock density on linear scales, summing these and mapping them onto a relative-risk scale. If the degree-days never reach the required temperature (zero risk days), the compound risk was also assumed to be zero.

Livestock data from the 2007 agricultural census were obtained from the Department of Agriculture National Agricultural Statistics Service (USDA-NASS) (http://www.nass.usda.gov). We calculated total livestock densities by summing together cattle and calf, sheep and lamb, and goat populations (the most common hosts for RVFV) at the county level. In the small 


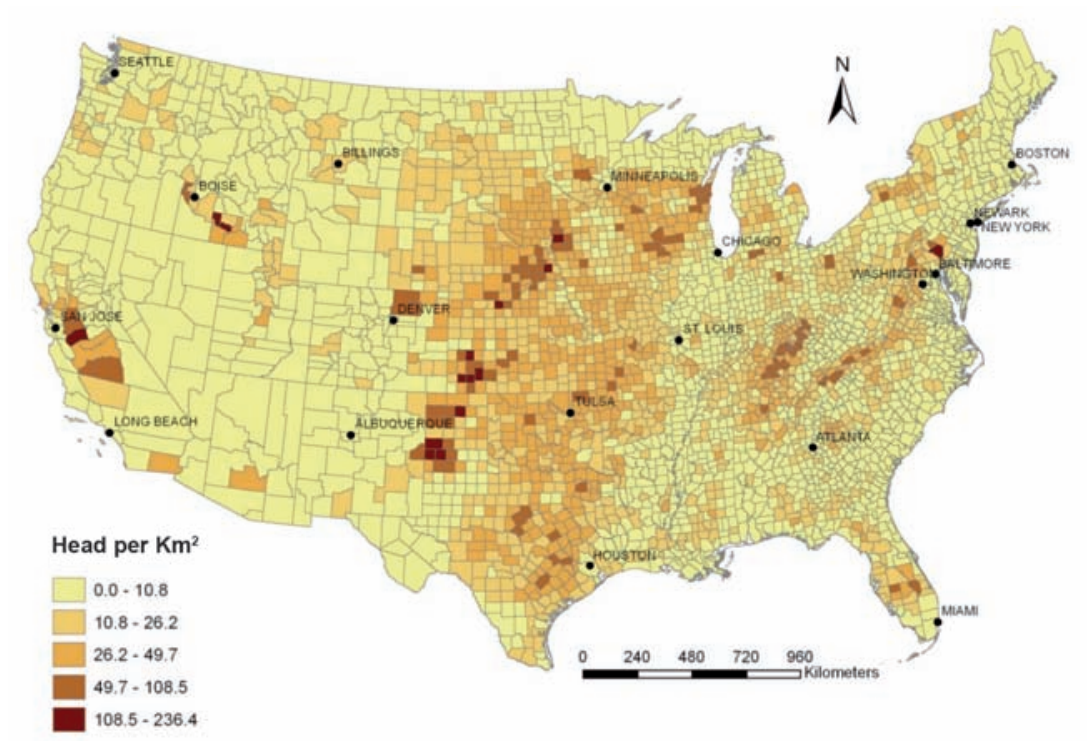

Fig. 1. Livestock density by US county in 2007 (data from USDA-NASS).

percentage of cases where population numbers for specific counties were withheld by the USDA to protect privacy, we back-calculated the populations by apportioning the state total across the unreported counties in proportion to the number of farms in each county. The total livestock densities are shown in Fig. 1.

We performed an in-depth analysis on the 14 states and six international airports identified by Kasari et al. (2008) as the most likely entry points for the virus. In addition to assessing the degree-day totals using the WNV threshold value of 76 degree-days as determined by Konrad et al. (2009) in California, we evaluated the transmission risk for \pm 20 degree-days $(28.5 \%)$ in each of these critical regions. It is probable that ${ }^{\circ} \mathrm{D}$ for RVFV in $\mathrm{C} x$. tarsalis does not precisely match that for WNV in $C x$. tarsalis, introducing a great deal of uncertainty into our transmission risk predictions. The choice to vary ${ }^{\circ} \mathrm{D}$ by \pm 20 degree-days is not tied to any particular prediction of the threshold value for RVFV. However, other studies have used values such as 109 degree-days (Reisen et al., 2006) and 82 degree-days (Schrag et al., 2011) for the ${ }^{\circ} \mathrm{D}$ of WNV transmission in Culex spp., which provides an idea of the basic variation of ${ }^{\circ} \mathrm{D}$ for different mosquito species and virus genotypes. We varied ${ }^{\circ} \mathrm{D}$ by $\pm 28.5 \%$ to get a sense of how different values affect the risk transmission estimates, rather than illustrate a precise range of possibilities.

\section{Results}

The predicted number of annual risk days provides a comprehensive view of temperature-based transmis- sion risk in the continental USA (Fig. 2). The number of risk days per year varied from zero in the very north of the country and in high elevations of the Rocky Mountains to 325 in southernmost Florida. The highest transmission-risk areas (reddish hues in Fig. 2) included the Southwest, specifically southeast California and southwest Arizona, and much of southern Texas and Florida. The southern states and the central valley of California were at increased risk, while the eastern seaboard, the midwest, and the lower parts of the intermountain west were all at moderate risk. Northern states and high altitude regions remain always at low risk.

In order to evaluate the effects of livestock density on RVFV transmission risk, we examined the compound risk map of normalized transmission risk days and livestock density (Fig. 3). In general, this map showed a similar pattern as the temperature-based map with risk being high in the south and in California and low in the north and in the Rocky Mountains. However, certain areas of high livestock density in the midwest, the central valley of California, and even Pennsylvania and Idaho, showed levels of compound risk on par with those of the southern states: note for example the elevated risk in northwest Texas and the significantly elevated risk in southeast Pennsylvania. The central valley of California turned out to be of higher relative risk, while that of southwest Arizona is reduced due to the lower proportions of livestock in those areas. Fig. 3 is thus a refinement on the relative risk of transmission with some areas showing elevated and others a reduced level of risk. 


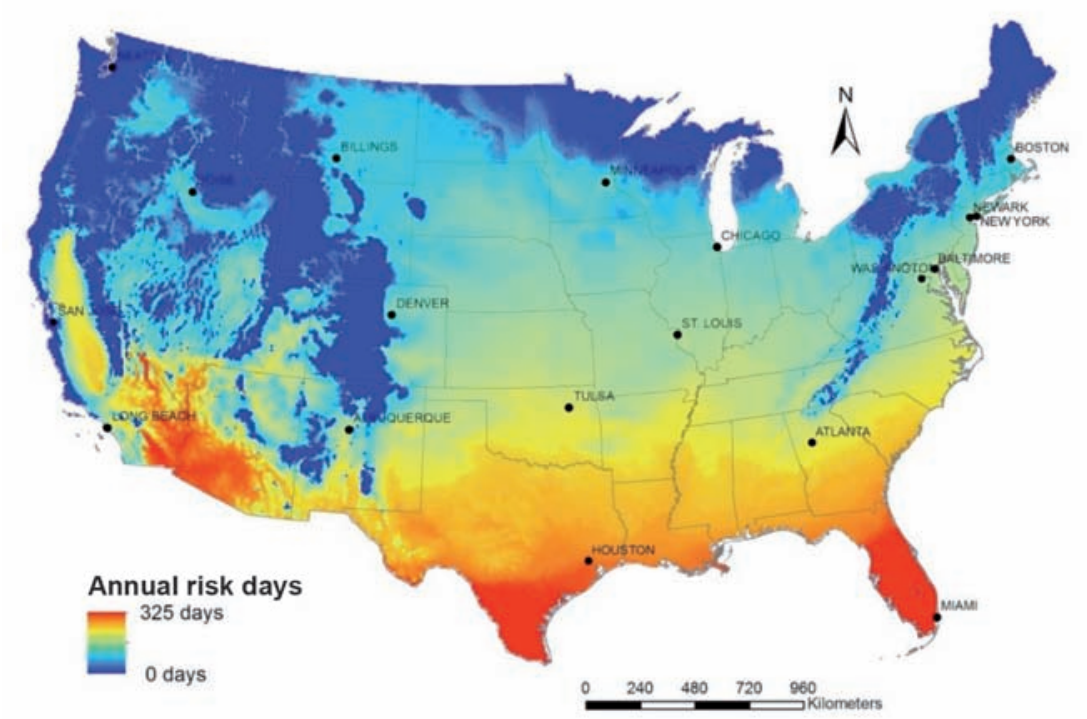

Fig. 2. Total temperature-based risk days over the course of a year.

The risk for RVFV transmission can also be inspected on a daily basis for the entire country grid (Fig. 4). Any day of the year can be mapped to show regions that are at risk for transmission (red shades) and regions that are not at risk (blue shades). The gradations in shading show the difference between the local summed degree-day temperature and ${ }^{\circ} \mathrm{D}$ (76 degreedays). Strong coloring represents degree-day sums much higher or lower than 76 degree-days, while lighter tones are closer to 76 degree-days. In this example we compared six dates to demonstrate the spatial rise and diminishment of risk during the year.
On February 1, only the southernmost tip of Florida was at risk; by April 1, southern Florida and the southern tip of Texas were at risk; on June 1, most of the south and the central valley of California were at risk; on August 1, the majority of the states were at risk; October 1 showed lessening of the risk resembling that of June; and the risk on December 1 was again limited to the southern tip of Florida.

Our analyses can be used to more closely examine the risk of transmission at the states (Fig. 5) and the international airports (Fig. 6) identified by the Kasari et al. (2008) pathways analysis. The figures show the

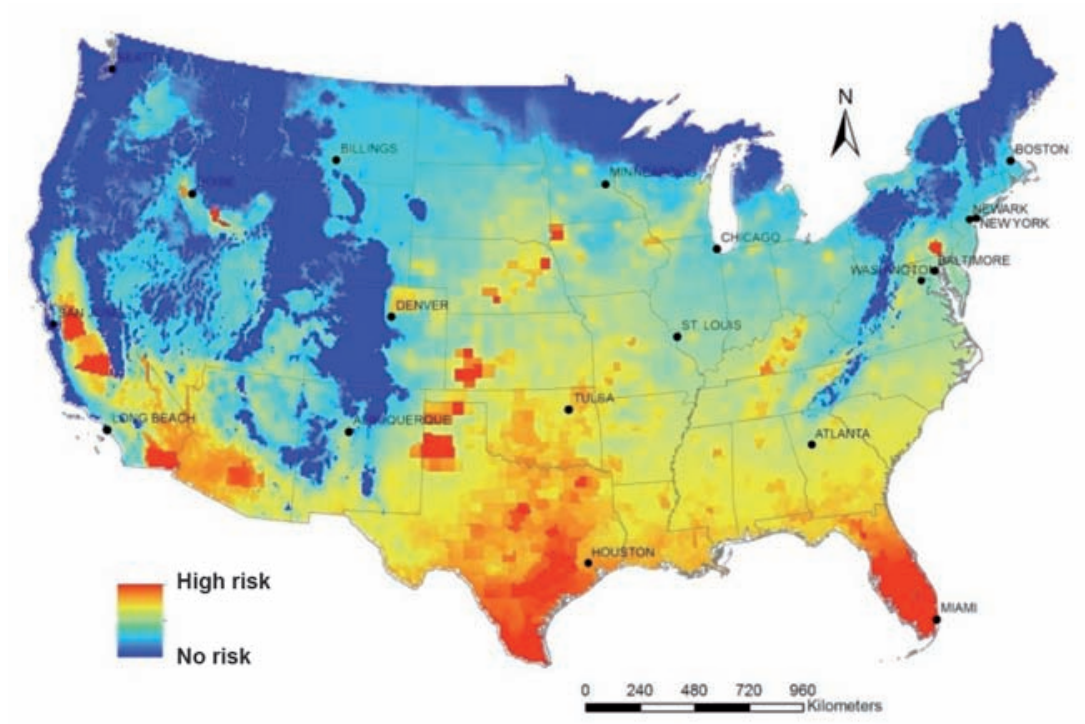

Fig. 3. Compound risk map based on the sum of normalized transmission risk and normalized livestock density. If the temperaturebased transmission risk is zero, the compound risk is also assumed to be zero. 


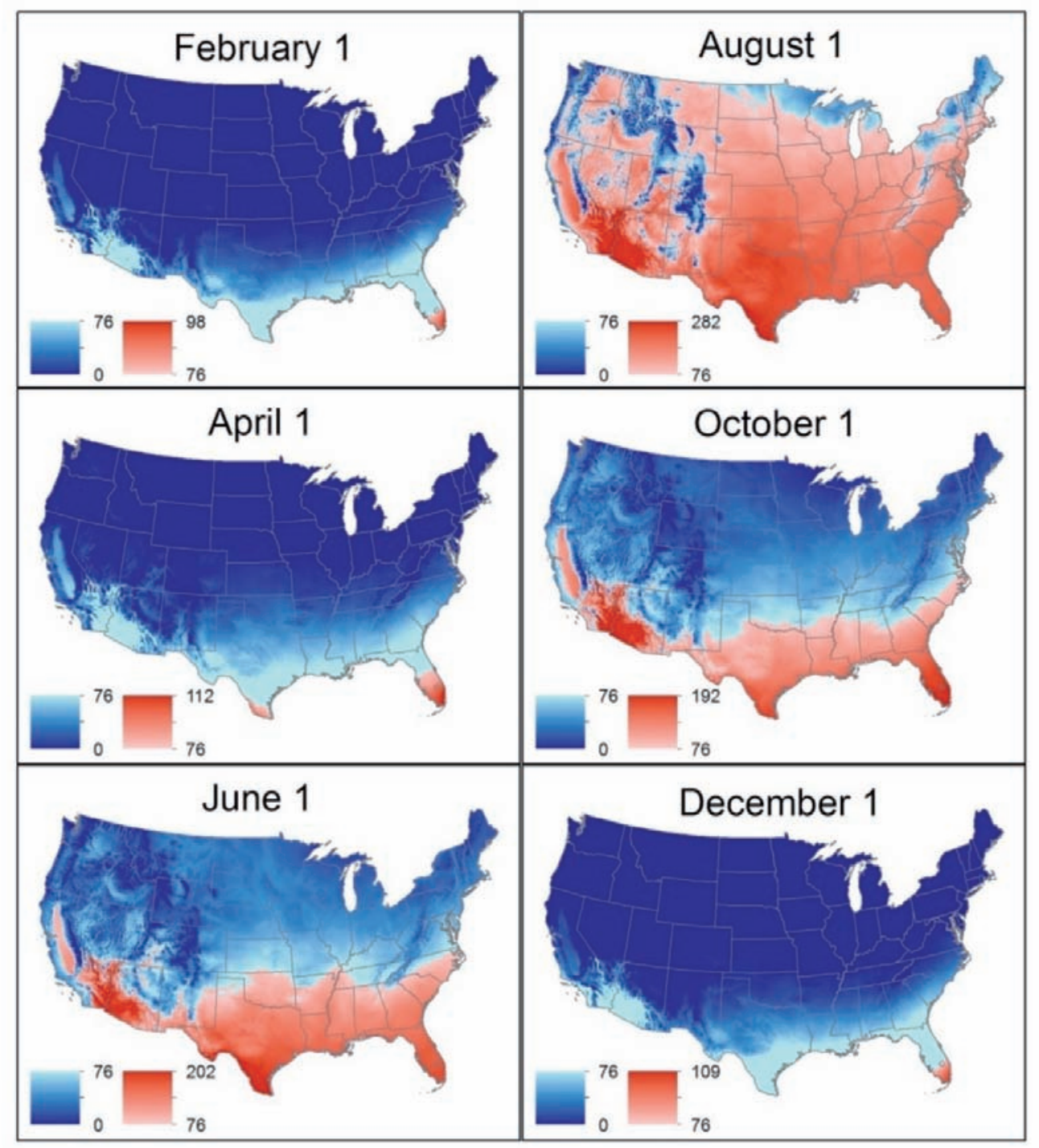

Fig. 4. Temperature-based transmission risk on select days throughout the year. Blue shades reflect no risk, red shades reflect risk. The lighter the shading, the closer the summed degree-day temperatures are to 76 degree-days.

dates that these locations were at risk, based on the historical temperature data averaged over the 10-year period from 1994-2003, using ${ }^{\circ} \mathrm{D}$ equal to 76 degreedays. The graphs also show the effect on the length of the "risk season" of varying ${ }^{\circ} D$ by \pm 20 degree-days $(28.5 \%)$.

Florida was shown to be the state most at-risk of transmission and virus establishment, with parts of the state at risk for 325 days of the year using the standard ${ }^{\circ} \mathrm{D}$ equals 76 degree-days scenario. If ${ }^{\circ} \mathrm{D}$ is lowered to 56 degree-days, however, much of the state becomes at-risk throughout the entire year. In general, the number of days carrying transmission risk in a state decreased inversely with latitude, to a minimum of 57 risk days per year in Maine (July and part of
August). The same pattern was true for the major airports, with risk days per year varying from 187 in Houston (with April as the onset of risk) to 91 at John F. Kennedy International Airport (JFK) in New York (with late June as the onset of risk). Under the ${ }^{\circ} D$ equals 56 degree-days scenario, the number of risk days annually varied from 215 in Houston to 107 at JFK, whereas there were 163 risk days per year predicted in Houston and 71 at JFK under the ${ }^{\circ} D$ equals 96 degree-days scenario. Evaluated at the six airports, there was a $12.8-22.3 \%$ decrease in the number of annual risk days associated with increasing ${ }^{\circ} \mathrm{D}$ by $28.5 \%$, and a $14.0-18.1 \%$ increase in the number of annual risk days associated with reducing ${ }^{\circ} D$ by $28.5 \%$. The effect of changing ${ }^{\circ} \mathrm{D}$ fell within a similar 


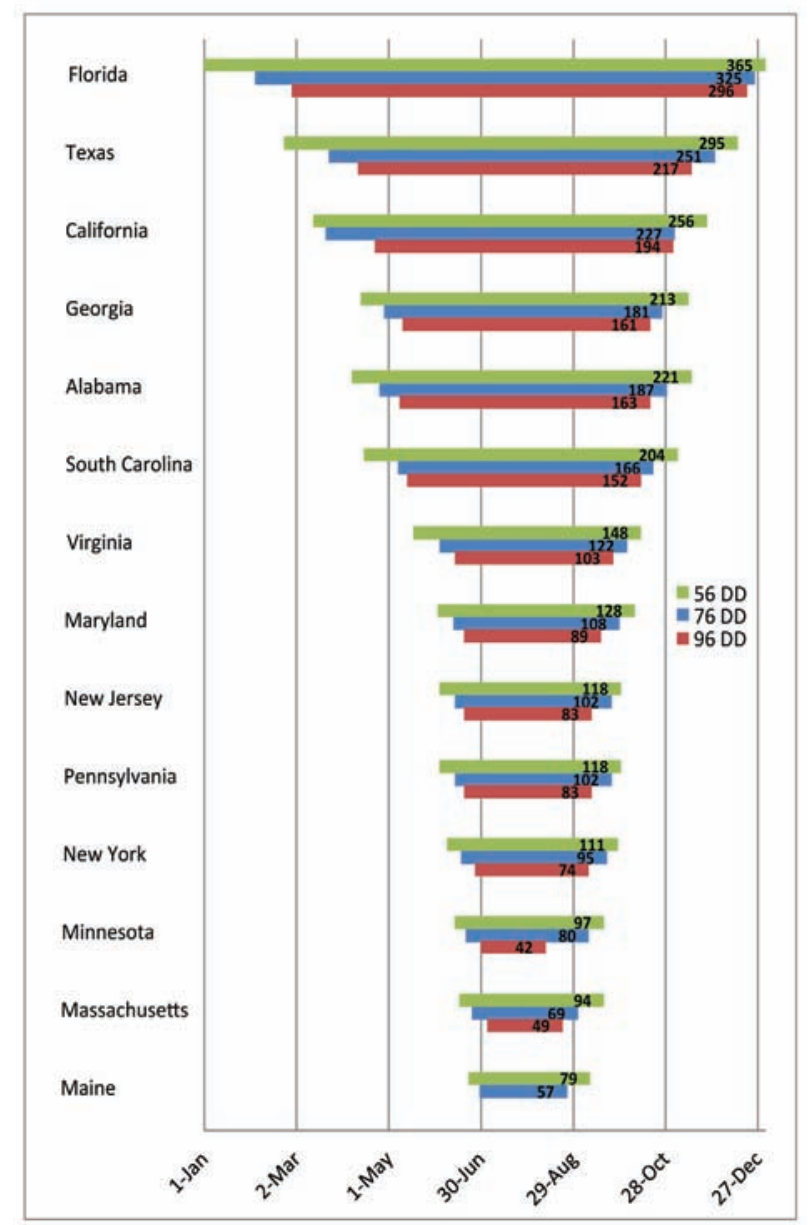

Fig. 5. The predicted "risk season" of the 14 states deemed most at risk by pathways analysis (Kasari et al 2008), shown with three different values of ${ }^{\circ} \mathrm{D}$. The total length (in days) of the risk season is shown to the right of each bar.

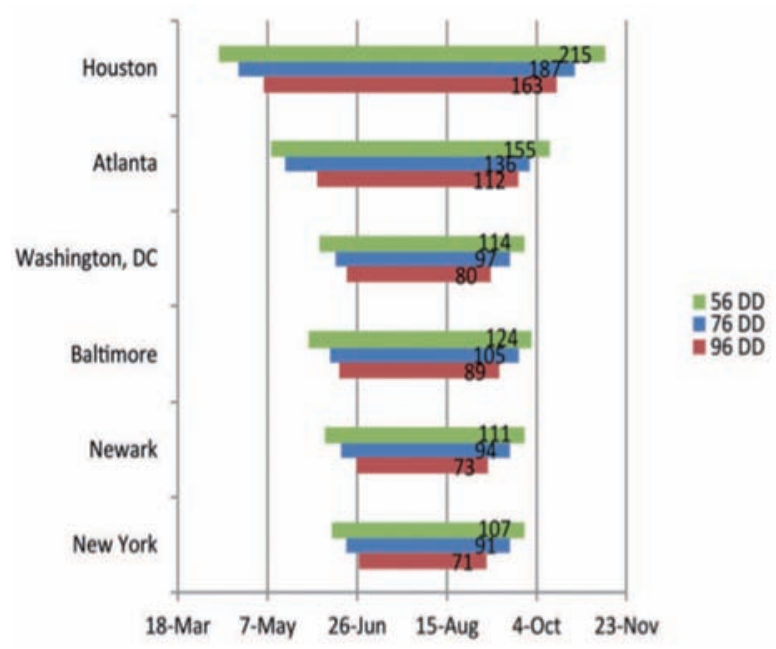

Fig. 6. The predicted "risk season" of the 6 international airports deemed most at risk the pathways analysis, shown with three different values of ${ }^{\circ} \mathrm{D}$. The total length (in days) of the risk season is shown to the right of each bar. range for the 14 pathways states, with the exception of the northern states of Maine, Minnesota and Massachusetts, which show a greater percent change due to the fact that these states had very few annual risk days under the standard ${ }^{\circ} \mathrm{D}$ equals 76 degree-days scenario.

\section{Discussion}

The transmission risk maps and graphs of local risk seasons were designed to be used by risk managers and local vector control districts to target regions and dates in need of surveillance for possible entry and establishment of RVFV into the USA. Although the main entry points had already been identified by pathways analysis (Kasari et al., 2008), this study allows risk managers to focus efforts specifically upon the risk seasons and not spend time and money on surveillance and/or control methods at times of the year when RVFV transmission risk is not possible.

To demonstrate how this information can be best used, we focused on an area of particularly high risk in the northeastern USA. Four of the major entry-point airports (JFK, Washington Dulles, Newark, and Baltimore) are located within several hundred kilometers of each other. Nearby is Lancaster County, Pennsylvania, home to a large community of Amish people and a high livestock density (primarily dairy cows). Lancaster is the only very high livestock density county located within $100 \mathrm{Km}$ of any of the major entry-point airports. This region should be viewed as at special risk as it is home to multiple entry pathways for RVFV, has a large population of reservoir animals, and is at risk for over three months of the year. The risk maps allowed us to chart a detailed progression of transmission risk at the onset of the risk season (Fig. 7). On June 9, there was no transmission risk in the region. Two days later, Baltimore/Washington International Airport was at risk. In another two days, Washington Dulles was also at risk, and the at-risk region was bordering Lancaster county. On June 15, the southern tip of the Lancaster country was at risk, and on June 17, most of the county was at risk as well as Newark International Airport. By June 19, all four major airports as well as Lancaster county were at risk of RVFV transmission, and this risk remained constant in the region through September. Extra precautions might be warranted in the summer months, as highrisk areas, such as this one, are the most likely regions for RVFV both to enter, and to become established, in the USA. Although the livestock densities are not as high in the vicinities of Atlanta and Houston, these 


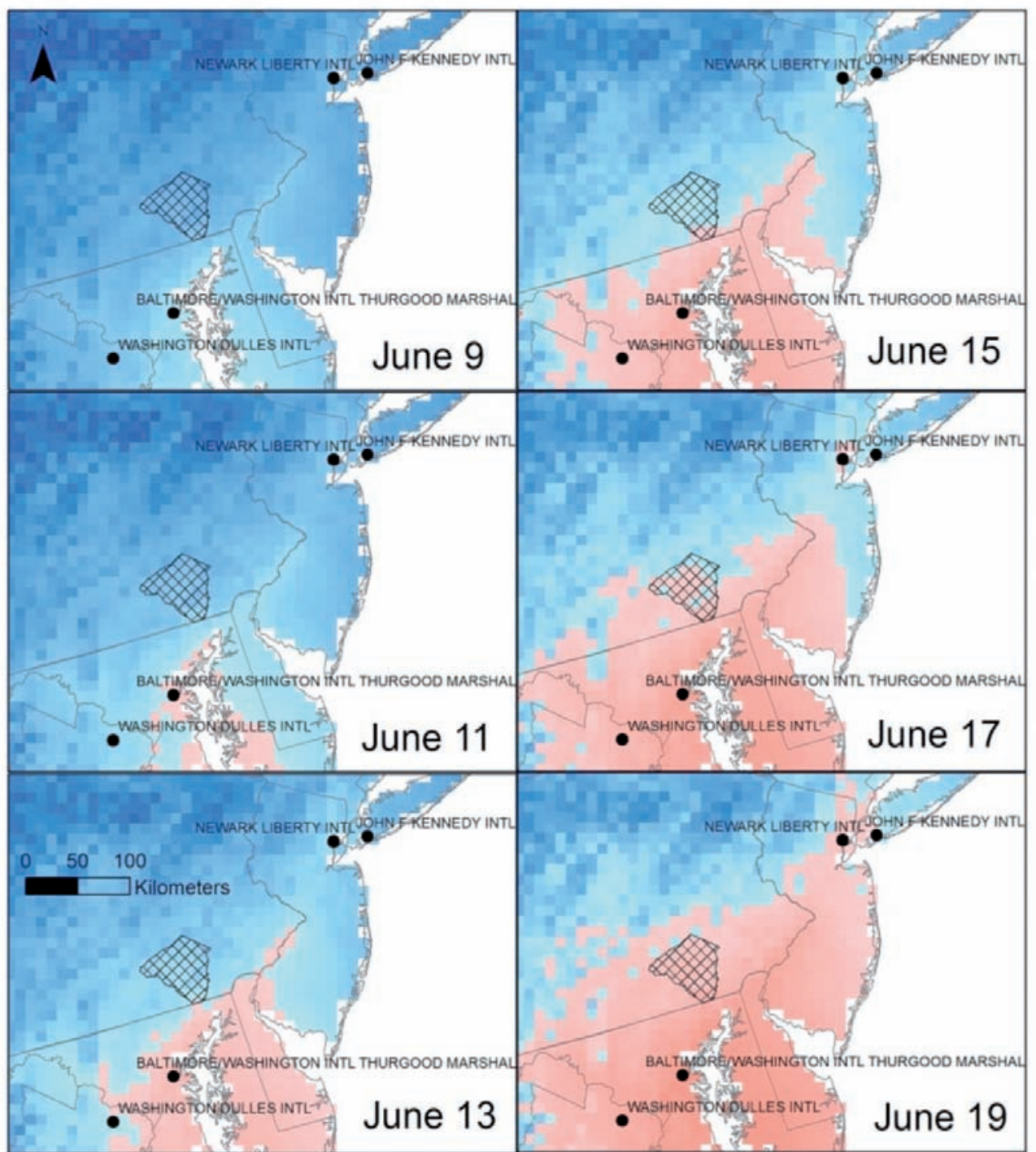

Fig. 7. The onset of transmission risk in the region including four of the major RVFV-entry airports and the livestock-dense Lancaster county, Pennsylvania (crosshatched area). Red shades show at risk areas, blue shades show not at-risk areas; the lighter shades reflect degree-day sums closer to ${ }^{\circ} \mathrm{D}$ (in this case, 76 degree-days).

southern regions have much longer risk seasons and should be considered for monitoring as well. By knowing the risk seasons of likely entry points, monitoring can be targeted towards the appropriate time of year. Outside of the risk season, there is minimal chance of RVFV becoming established, as the temperatures are not high enough to allow vector-borne disease transmission. Other areas of particularly high risk include Florida, Atlanta, southwest Nebraska, southern California and Arizona, and the central valley of California.

If global warming follows the predictions of the Intergovernmental Panel on Climate Change (IPCC) (http://www.ipcc.ch/), onset dates of the risk seasons would tend to come slightly earlier and the end dates slightly later than those predicted based on the historical averages. Comparison of temperature data from a standard Global Climate Model for the year 2030 with the historical DAYMET data shows an increase of annual risk days in Nebraska from about three months to four months (Konrad et al., 2011). Although current temperatures are not as warm as those predicted for 2030, they are somewhat warmer than the 1994-2003 temperatures upon which this analysis is based.

The most important variable in this study is ${ }^{\circ} \mathrm{D}$, for which we use 76 degree-days based on the time and temperature required for $C x$. tarsalis to transmit WNV. Obviously, it would be preferable to use a parameter that specifically reflects the time and tem- 
perature necessary for Cx. tarsalis to transmit RVFV. Laboratory experiments are currently underway to determine this parameter (MJ Turell, personal communication) and once it is known, it is a straightforward task to update the outcome of the model through new input data and thus produce new risk maps. In addition, some North American Ae. vexans mosquitoes have been shown to transmit RVFV, although the same species from another part of the country do not (Turell et al., 2010), suggesting that regional calibration of the model would be the ideal approach. If and when RVFV does come to the USA, temperatures can be monitored in areas where RVFV is being transmitted by local vectors in order to field calibrate the laboratory numbers. We are currently working towards an online version of the model, which will allow users access to real-time risk assessment as well as the ability to vary the transmission parameters. Given knowledge of the appropriate parameters, the degree-day model can be used to assess transmission risk of not just RVFV, but any arbovirus.

The spatial analyses discussed here will be of most use within the hands of local vector control districts, who know when and where the local mosquito populations are active. The transmission maps only show where and when transmission is theoretically possible; when combined with mosquito abundance data, they will effectively target problem areas and dates where elimination efforts will do the most good.

\section{Acknowledgements}

This project was funded by the United States Department of Agriculture specific cooperative agreement \#5410-32000-01415.

\section{References}

Allen JC, 1976. A modified sine wave method for calculating degree-days. Environ Entomol 5, 388-396.

Daubney R, Hudson JR, Garnham PC, 1931. An undescribed virus of sheep, cattle and man from East Africa. J Pathol Bacteriol 34, 545-579.

Davies FG, Linthicum KJ, James AD, 1985. Rainfall and epizootic Rift Valley fever. Bull World Health Organ 63, 941-943.

Enserink M, 2002. West Nile's surprisingly swift continental sweep. Science, 297, 1988-1989.

Geisbert TW, Jahrling PB, 2004. Exotic emerging viral diseases: progress and challenges. Nat Med 10, S110-S121.

Hurlbut HS, 1973. The effect of environmental temperature upon the transmission of St. Louis encephalitis virus by Culex pipiens quinauefasciatus. J Med Entomol 10, 1-12.
Kasari TR, Carr DA, Lynn TV, Weaver JT, 2008. Evaluation of pathways for release of Rift Valley fever virus into domestic ruminant livestock, ruminant wildlife, and human populations in the continental United States. J Am Vet Med Assoc 232, 514-529.

Konrad SK, Miller SN, Reeves WK, Tietze NS, 2009. Spatially explicit West Nile virus risk modeling in Santa Clara County, CA. Vector-Borne Zoon Dis 9, 267-274.

Konrad SK, Miller SN, Reeves WK, 2011. A spatially explicit degree-day model of Rift Valley fever transmission risk in the continental United States. Geo Journal 76, 257-266.

Lysyk TJ, 2010. Species abundance and seasonal activity of mosquitoes on cattle facilities in southern Alberta, Canada, J Med Entomol 47, 32-42.

Meegan JM, Bailey CL, 1988. Rift Valley fever. In T. Monath (Ed.), Arboviruses: Epidemiology and Ecology. Volume IV (pp. 51-76). Boca Raton, FL: CRC Press.

Moudy RM, Meola MA, Morin LL, Ebel GD, Kramer LD, 2007. A newly emergent genotype of West Nile virus is transmitted earlier and more efficiently by Culex mosquitoes. Am J Trop Med Hyg 77, 365-370.

Nasci RS, Moore CG, 1998. Vector-borne disease surveillance and natural disasters. Emerg Infect Dis 4, 333-334.

Pearson JE, 2000. Biological agents as potential weapons against animals. Biological warfare technical brief, 16 June 2000. Office International des Epizooties (OIE), Paris, 3 p.

Reisen WK, Meyer RP, Presser SB, Hardy JL, 1993. Effect of temperature on the transmission of western equine encephalomyelitis and St. Louis encephalitis viruses by Culex tarsalis (Diptera: Culicidae). J Med Entomol 30, 151-160.

Reisen WK, Fang Y, Martinez VM, 2006. Effects of temperature on the transmission of West Nile virus by Culex tarsalis (Diptera: Culicidae). J Med Entomol 43, 309-317.

Schrag AM, Konrad SK, Miller SN, Walker BL, Forrest SC, 2011. Climate-change impacts on sagebrush habitat and West Nile virus transmission risk and conservation implications for greater sage grouse. Geo Journal 76, 561-575.

Shaman J, Stieglitz M, Stark C, Le Blancq S, Cane M, 2002. Using a dynamic hydrology model to predict mosquito abundances in flood and swamp water. Emerg Infect Dis 8, 6-13.

Shaman J, Day JF, Komar N, 2010. Hydrologic conditions describe West Nile virus risk in Colorado. Int J Environ Res Public Health 7, 494-508.

Thornton PE, Running SW, White MA, 1997. Generating surfaces of daily meteorology variables over large regions of complex terrain. J Hydrol 190, 214-251.

Turell MJ, Rossi CA, Bailey CL, 1985. Effect of extrinsic incubation temperature on the ability of Aedes taeniorhynchus and Culex pipiens to transmit Rift Valley fever virus. Am J Trop Med Hyg 34, 1211-1218.

Turell MJ, Presley SM, Gad AM, Cope SE, Dohm DJ, Morrill JC, Arthur RR, 1996. Vector competence of Egyptian mosqui- 
toes for Rift Valley fever virus. Am J Trop Med Hyg 54, 136139.

Turell MJ, Linthicum KJ, Patrican LA, Davies FG, Kairo A, Bailey CL, 2008. Vector competence of selected African mosquito (Diptera: Culicidae) species for Rift Valley fever virus. J Med Entomol 45, 102-108.
Turell MJ, Wilson WC, Bennett KE, 2010. Potential for North American mosquitoes (Diptera: Culicidae) to transmit Rift Valley fever virus. J Med Entomol 47, 884-889.

Zou L, Miller SN, Schmidtmann, ET, 2007. A GIS tool to estimate West Nile virus risk based on a degree-day model. Environ Monit Assess129,413-420. 